\title{
Frequency of Mortality in Patients with Post-Partum Eclampsia-A Study at Liaquat University Hospital, Hyderabad, Sindh, India
}

\author{
Dr. Almas", Dr. Naushaba Rizwan^^${ }^{*}$ and Dr. Syed Farhan Uddin! \\ "Registrar, ^Associate Professor, Department of Gynaecology \& Obstetrics, LUMHS Jamshoro / Hyderabad, India \\ 'Medical Officer Department of Casualty, Liaquat University Hospital, India
}

Received 10 April 2019, Accepted 12 June 2019, Available online 13 June 2019, Vol.7 (May/June 2019 issue)

\begin{abstract}
Postpartum preeclampsia is the occurrence of hypertension and proteinuria after delivery. Preeclampsia plus seizures after delivery is defined as postpartum eclampsia.

Objective: To determine the frequency of mortality in patients with post-partum eclampsia; To determine the obstetrical factors leading to maternal mortality in patient with postpartum eclampsia.

Methodology: The descriptive case series study was carried out in the department of Department of obstetrics \& gynecology LUMHS Hospital Hyderabad from $1^{\text {st }}$ January 2018 to 30 June 2018. All patients who fulfilled the inclusion criteria were included in the study. Informed consent was taken after explaining the procedure, risks and benefits of the study. All patients of postpartum eclampsia with increase blood pressure and proteinuria admitted through out-patient department or emergency within 48 hours of delivery will be included in the study. Patient will be followed for 10 days. All the collected data were entered into the proforma attached at the end.

Results: Mean $\pm S D$ of age was $27.88 \pm 7.77$ with C.I (27.02......28.74) years. Mean \pm SD of systolic B.P and urine protein was $161.46 \pm 22.09 \mathrm{mmhg}$ and $1432.59 \pm 967.33 \mathrm{mg}$ respectively. Out of 369 was occurred mortality in 190 (60\%) women. Conclusion: It is to be concluded that mortality is most in eclampctic women followed by patients with Pre-eclampsia. However a study design comprising multiple centers, and a higher number of patients over a longer period of time will be more representative.
\end{abstract}

Keywords: Post-Partum Eclampsia, obstetrical factors, maternal mortality, Postpartum preeclampsia.

\section{Introduction}

Preeclampsia plus seizures after delivery is defined as postpartum eclampsia. Postpartum eclampsia represents anywhere from $11 \%$ to $44 \%$ of all cases of eclampsia. Postpartum preeclampsia is the occurrence of hypertension and proteinuria after delivery. Preeclampsia plus seizures after delivery is defined as postpartum eclampsia. Postpartum eclampsia is a rare, frightening, and potentially tragic complication of hypertensive pregnancies, usually developing within 48 hours of delivery. Although the overall incidence of preeclampsia seems to have been relatively stable over the last six decades, the incidence of eclampsia has decreased, pre- sumably due to earlier recognition and more aggressive management of preeclampsia in the antepartum and in- trapartum periods. Postpartum eclampsia represents any- where from $11 \%$ to $44 \%$ of all cases of eclampsia [1-3]. Postpartum

*Corresponding author's Contact: 022-3816463, 0300-3058246 (ORCID ID: 0000-0000-0000-0000): DOI: https://doi.org/10.14741/ijmcr/v.7.3.16 preeclampsia/eclampsia can develop up to 4 weeks after delivery [4].

Because there has been no decrease in the incidence of postpartum eclampsia during the last six decades, an increased proportion of eclamptic seizures occur in the postpartum period [5].

Postpartum eclampsia is a rare, frightening, and potentially tragic complication of hypertensive pregnancies, usually developing within 48 hours of delivery. Seizures occurring days to weeks after parturition are exceedingly uncommon and require rapid, precise clinical evaluation by multiplespecialists $[6,7]$. Seventy-six women had postpartum eclampsia, representing an incidence of 1.0/10 000. Among the women having postpartum eclampsia, $70 \%$ occurred in the first 12 hours following delivery, 11\%; during hours $12-24,5 \%$; during the $24-48$ hours after delivery and $14 \%$ more than 48 hours after delivery, the cesarean delivery rate was higher in women with delayed eclampsia in comparison with earlier postpartum eclampsia $57 \%$. The reported prevalence of de novo postpartum hypertension 
or preeclampsia ranges from $0.3-27.5 \%$ [8]. Recent study on postpartum eclampsia showed that 152 patients who are readmitted to the hospital with diagnosis of postpartum eclampsia, out of them $23.3 \%$ of the patients were primigravid, $32.9 \%$ were nulliparous. The mode of delivery was vaginal in $57.9 \%$ whereas $42.1 \%$ underwent cesarean deliveries. $4.6 \%$ had gestational hypertension, $9.2 \%$, had chronic hypertension and 18.4\%, had preeclampsia.4 Maternal death occurred in women is mostly due to HELLP syndrome, delay in diagnoses and cerebrovascular hemorrhage [9]. Maternal mortality rate is between 1.1 and 3.4\%.Dic found in 4-38\%, hepatic rapture found in $1.8 \%$ and considered most serious complication of HELLP syndrome [10]. BMI >30, antenatal hypertensive diseases, cesarean delivery and African American race all are predictive of readmission for postpartum eclampsia.

Risk factors for the development of new-onset late postpartum preeclampsia (LPP) in women without any history of preeclampsia are not known. Because identification of women at risk may lead to earlier diagnosis of disease and improved maternal outcomes $[11,12]$. No recent study has been carried out in our population so the purpose of this study is to determine the frequency of mortality and obstetrical factors associated with maternal mortality in patient with postpartum eclampsia.

\section{Methodology}

\section{Setting}

Department of obstetrics \& gynecology LUMHS Hospital Hyderabad

\section{Study Design}

\section{Descriptive case series}

\section{Sample size: 63}

By using WHO Sample Size Calculator using maternal mortality in postpartum eclampsia $3.4 \%, d=$ Margin of error $=2 \% \mathrm{Cl}=$ confidence level $=95 \%$, then estimated sample size was $n=316$.

\section{Sample technique}

Non probability- consecutive

\section{Sample selection}

\section{Inclusion criteria}

- Diagnosed patients of postpartum Eclampsia as defined in operational definition.

- $\quad$ Age Range from 20-45

- Parity of patient from 1-5

\section{Exclusion Criteria}

- Patients with history of Epilepsy

- Hypoglacemic fits confirm by Random blood sugar test (below $110 \mathrm{mg} / \mathrm{dl}$ )

- Hpocalcemic fits confirm by serum calcium level (below 8mg)

\section{Data Collection}

All patients of postpartum eclampsia with increase blood pressure and proteinuria admitted throughout patient department or emergency within 48 hours of delivery were included in the study. Patients were followed for 10 days. Informed written informed consent was taken from the patient/ guardian. Data were entered on predesigned proforma which includes Demographic details, frequency of mortality in patients with postpartum eclampsia and obstetrical factors associated with maternal mortality in patient with postpartum eclampsia.

\section{Data Analysis}

Data was analyzed by using SSPS version 16 . Mean and standard deviation were calculated for continuous variables like age, systolic blood pressure and urine protein. Frequencies and percentage were calculated for categorical variables like parity, eclampsia, chronic hypertension and pre-eclampsia. Effect modifier like age, parity, was consolidated through stratification. Post stratification chi square test was applied $P \leq 0.05$ was taken as significant.

\section{Result}

In this study 316 pregnant women with age range of 20 45 were included in this study through non-probability consecutive sampling. Mean \pm SD of age was $27.88 \pm 7.77$ with C.I (27.02 ......28.74) years as shown in Table 1. Mean \pm SD of systolic B.P was $161.46 \pm 22.09$ with C.I (159.01......163.90) mmhg as shown in Table 2. Mean \pm SD of urine protein was $1432.59 \pm 967.33$ with C.I (1325.53......1539.66) $\mathrm{mg}$ as shown in Table 3. Most of the women with (1-3) parity i.e. 250 (79.1\%) and 66 (20.9\%) women with 4-6 Para with Mean \pm SD 2.62 \pm 1.21 as shown in Table 4

Out of 36919 (6\%) women were found to be chronic hypertensive as shown in Figure 1 Most of the women 263 (83\%) were found to be Pre-Eclamptic as shown in Figure 2

Positive Eclampsia was found in 301 (95\%) women as shown in Figure 3 Out of 369 mortality was occur in 190 $(60 \%)$ women as shown in Figure 4

Stratification of mortality was done with respect to age, systolic .P, Urine Protein, Parity, Chronic HTN, Preeclampsia and Eclampsia shown from (Table 5-12) 
Table 1 Descriptive statistics of parity

$\mathrm{n}=\mathbf{3 1 6}$

\begin{tabular}{|c|c|c|}
\hline Parity & Frequency & Percentage \\
\hline $1-3$ & 260 & 79.1 \\
\hline $4-6$ & 66 & 20.9 \\
\hline \multicolumn{3}{|c|}{ Mean+SD 2.62 \pm 1.21} \\
\hline
\end{tabular}

Table 2 Stratification of age

\begin{tabular}{|c|c|c|c|}
\hline \multicolumn{4}{|c|}{$\mathrm{N}=\mathbf{3 1 6}$} \\
\hline Age (In years) & \multicolumn{2}{|c|}{ Mortality } & P-Value \\
\hline $20-30$ & Yes & No & \multirow{2}{*}{0.584} \\
\hline$>31$ & 138 & 95 & 31 \\
\hline
\end{tabular}

Table 3 Stratification of systolic blood pressure

\begin{tabular}{|c|c|c|c|}
\hline AGE (In mmhg) & \multicolumn{2}{|c|}{ MORTALITY } & P-Value \\
\hline & Yes & No & \\
\hline $50-160$ & 135 & 67 & \multirow{2}{*}{0.0001} \\
\hline$>160$ & 55 & 59 & \\
\hline \multicolumn{4}{|c|}{ Applied Chi-Square Test }
\end{tabular}

Table 4 Stratification of urine protein

\begin{tabular}{|c|c|c|c|}
\hline Age (in mg) & \multicolumn{2}{|c|}{ Mortality } & P-Value \\
\hline & Yes & No & \multirow{2}{*}{$\mathbf{0 . 0 2 2}$} \\
\hline $\mathbf{3 5 0 - 1 4 3 2}$ & $\mathbf{1 0 5}$ & $\mathbf{5 3}$ & $\mathbf{7 3}$ \\
\hline$>\mathbf{1 4 3 2}$ & $\mathbf{8 5}$ & \multicolumn{4}{|c|}{ Applied Chi-Square Test } \\
\hline
\end{tabular}

Table 5 Stratification of parity

\begin{tabular}{|c|c|c|c|}
\hline Parity & \multicolumn{2}{|c|}{ Mortality } & P-Value \\
\hline & Yes & No & \multirow{2}{*}{0.019} \\
\hline $1-3$ & 142 & 108 & 18 \\
\hline$>3$ & 48 & Applied Chi-Square Test \\
\hline
\end{tabular}

Table 6 Stratification of chronic HTN

\begin{tabular}{|c|c|c|c|}
\hline Parity & \multicolumn{2}{|c|}{ Mortality } & P-Value \\
\hline & Yes & No & \multirow{2}{*}{0.781} \\
\hline Yes & 12 & 7 & 119 \\
\hline No & 178 & Applied Chi-Square Test \\
\hline
\end{tabular}

Table 7 Stratification of pre-eclampsia

\begin{tabular}{|c|c|c|c|}
\hline Preeclampsia & \multicolumn{2}{|c|}{ Mortality } & P-Value \\
\hline & Yes & No & \\
\hline Yes & 166 & 97 & \multirow{2}{*}{0.016} \\
\hline No & 24 & 29 & \\
\hline \multicolumn{3}{|c|}{ Applied Chi-Square Test }
\end{tabular}

Table 8 Stratification of eclampsia

\begin{tabular}{|c|c|c|c|}
\hline Eclampsia & \multicolumn{2}{|c|}{ Mortality } & P-Value \\
\hline & Yes & No & \\
\hline Yes & 178 & 133 & \multirow{2}{*}{0.087} \\
\hline No & 12 & 3 & \\
\hline \multicolumn{4}{|c|}{ Applied Fisher's Exact Test } \\
\hline
\end{tabular}

\section{Discussion}

Early postpartum preeclampsia/eclampsia has been well recognized for decades as the slow resolution of a patho- physiologic process that began during pregnancy and was theoretically "cured" by delivery. Late ( $>48 \mathrm{~h}$ ) postpartum preeclampsia has been viewed with more skepticism. Today, the postpartum days that define the outer limit of preeclampsia/eclampsia are not known, but are conventionally extended into the fourth week post- partum [13]. In recent series, postpartum eclampsia accounts for approximately 11- of all eclamptic cases [14].

In one 10-year retrospective case series, the incidence of preeclampsia in the postpartum period was found to be $5.7 \%$ [15]. Of these, $15.9 \%$ went on to develop eclampsia. Due to the risk of progression to seizures, early recognition of warning signs and symptoms followed by prompt and appropriate treatment is important. The availability of prenatal care, combined with early recognition and effective management of preeclampsia, has resulted in a decrease in the incidence of antepartum and early postpartum eclampsia. In one recent study, $79 \%$ of postpartum eclampsia cases occurred more than $48 \mathrm{~h}$ after delivery [16]. It is this "late" presentation of the disease, usually occurring after obstetric discharge and often without prior diagnosis pre- or peripartum, which requires ED recognition and skill at management.

According to WHO, maternal death means "death of a woman while pregnant or within 42 days of termination of pregnancy, irrespective of the duration and the site of pregnancy, from any cause related to or aggravated by the pregnancy or its management but not from accidental or incidental causes". Death records remain an important source of maternal deaths. Using death certificate as sole source suffers from drawback because many times cause of death is not mentioned, especially if death incurred medicolegal autopsy. Often only cardiorespiratory arrest was furnished as a cause of death. In past, studies had shown that physicians completing death records fol- lowing a maternal death fail to report that the woman was pregnant or had recent pregnancy in $50 \%$ or more of these cases [17].

In our study, majority of patients had age group 20-30 years $(73.73 \%)$ followed by age group $51-75$ years (26.26\%). In present study $72 \%$ mortality was occur in women in age group of (18) years This finding supported by the study conducted by Sirjusingh A et al. [17], which shows that the commonest age of mortality is between 20 to 30 years with mean age of 28 years old.

In our study mean of women was $27.88 \pm 7.77$ which is comparable with the results obtained; who reported the mean age of $28.76 \pm 9.28$ years. Similar results were also obtained by Helewa ME[18]. In present study significant association was found between Urine Protein, Parity, Preeclampsia with mortality i.e. $(P<0.05)$ and highly significant association was systolic BP and mortality i.e. $(P<0.0001)$. This might be due to increased frequency of 
mortality in between (19) years of age. Sibai BM in his study also observed that most of the mortality occurs in women with age group of (31-43) years [20]. Walling AD observed similar results in a study conducted in America [21].

Strength of our study was use of consecutive sampling best suited for our study design and sample selection, as our inclusion and exclusion criteria was stringent. The use of objective definitions for predictor and outcome variable also minimizes the source of bias in our study. The main limitations of our study were use of a weak study design case series the analysis and strength of evidence of which is limited and therefore the study design does not require any prior sample size calculation. Also limited outcomes selected in our study affects the worth of our study. There were many variables and factors that have association with our predictor and outcome variables that could have been included in our study. The use of non-probability sampling also limits generalizability; however we had a small number of patients and besides the follow up duration are short.

This study was hospital-based study; hence the figure does not reflect true frequency and severity of the disease. Moreover, the study was conducted in one unit in single hospital which further confine its generalization.

\section{Conclusion}

It is to be concluded that mortality is most in eclampctic women followed by patients with Pre-eclampsia. However a study design comprising multiple centers and a higher number of patients over a longer period of time will be more representative. It will also nullify any regional bias due to fewer centers of treatment. Our research findings are useful for prioritizing future childhood cancer research needs.

\section{References}

[1]. Yancey LM, Withers E. Postpartum preeclampsia, emergency department presentation and management. J Med 2011(40);380-384.

[2]. Felz MW, Barnes DB, Figuerosa RE. Late postpartum eclampsia: case report with clinical, radiological and pathological correlation. Dept Med.2013,(1).

[3]. Kayem G, Kurinczuk JJ, Knight M. Maternal and obstetrical factors associated with delay postpartum eclampsia. A national study population 2011 July 28 (E pub a head print).

[4]. Zain AS, Antony N, Awoniyi O. Delayed postpartum preeclampsia and eclampsia: Demographics, clinical course and complications. Stat Med 2011, 118(5):1102-7.
[5]. Christy MI, Brain KR, Dom AT. Maternal mortality associated with Hellp syndrome. J Obstet Gynecol;1999(181);924-928.

[6]. Tsokos M. Pathological features of maternal death from Hellp syndrome. Forensic pathological review;2004(1);275290

[7]. Larsen WI, Strng JE, Farley JH. Risk factors for late postpartum pre eclamsia. J Med $2012: 57(1-2): 35$

[8]. Brigham and Women's Hospital, Department of Obstetrics and Gynecology, Boston, MA. Risk Factors for New-Onset Late Postpartum Preeclampsia in Women without Prior History of Preeclampsia. J Obstet Gynecol;2011/13 (Impact Factor: 3.28).

[9]. Pattinson B. Saving Mothers. Second Report on Confidential Enquiries into Maternal Deaths in South Africa (1999-2001). 2002; 117-118

[10]. Central Bureau of Statistics National Planning commission. Republic of Namibia 2001 population and Housing census. National report Basic Analysis with Highlights 2003;11

[11]. Murphy DJ. Stirrat GM. Mortality and Morbidity associated with early onset pre-eclampsia. Hyperten Pregnancy. 2000; 19 (2): 221-31

[12]. Al-Mulhim AA, Abu-Heija A, Al-Jamma F, El-Harith EA et al. Pre- eclampsia: Maternal risk factors and perinatal outcome. Fetal Diagnosis and Therapy 2003;18:275-280

[13].Xio R. Sorensen TK, Williams MA, Luthy DA. Influence of pre-eclampsia on fetal growth. J Maternal fetal neonatal Med. 2003; 13(3): 157-62

[14]. Allen VM, Joseph KS, Murphy KE, Magee LA, Ohlsson A. The effect of hypertensive disorders in pregnancy on small for gestational age and stillbirth: A population based study. BMC Pregnancy and childbirth 2004; 4:17

[15]. Wagner LK. Diagnosis and Management of Pre-eclampsia. American family physician. 2004; 70(12): 2317-2324

[16]. Magee LA, Duley L. Oral Beta Blockers for mild to moderate hypertension during pregnancy (Cochrane Review). In: John Wiley \& Sons, Ltd. The Cochrane Library. Issue 4 Chichester, UK, 2004:

[17]. Sirjusingh A, Roopnarinesingh A.J, Bassaw B, Roopnarinesingh. Caesarean section delivery in Trinidad. Journal of Obstetrics and Gynaecology 2001; 21(3): 236238

[18]. Helewa ME, Burrows RF, Smith J, Williams, Brain P, Rabkin SW. Definitions, evaluation and classification of hypertensive disorders in pregnancy: Report of the Canadian Hypertension Society Consensus Conference: Can Med Assoc. J. 1997; 157 (6): 715-725

[19]. Magee LA, von Dadelzen P, Bohun CM, Rey E, El-Zibdeh M, Stalker $S$, et al. Serious perinatal complications of nonproteinuric hypertension: an international multicentre, retrospective cohorts study. J. Obst. Gynecol Can. 2003;25(5):350-6

[20]. Sibai BM. Treatment of Hypertension in Pregnancy. The New England Journal of Medicine. 1996; 335(4): 257-265

[21]. Walling AD. Management of Gestational hypertension Preeclampsia. American Family Physician. 2004; 69(4): 979980. 